\title{
ERBIUM IMPLANTATION IN STRONTIUM TITANATE
}

\author{
J.P. Araújo ${ }^{1}$, U. Wahl ${ }^{2}$, E. Alves ${ }^{3},{ }^{*}$ J.G. Correia ${ }^{3,4}$, T. Monteiro ${ }^{5}$, J. Soares ${ }^{5}$, L. Santos ${ }^{5}$ \\ and the ISOLDE Collaboration ${ }^{4}$ \\ ${ }^{1}$ IFIMUP, Fac. Ciências, Rua do Campo Alegre 657, P-4150 Porto, Portugal \\ ${ }^{2}$ IKS, Celestijnenlaan 200 D, B-3001 Leuven, Belgium \\ ${ }^{3}$ Instituto Tecnológico e Nuclear, E.N. 10, P-2685 Sacavém, Portugal \\ ${ }^{4}$ EP Div., CERN, CH-1211 Geneva 23, Switzerland \\ ${ }^{5}$ Departamento de Física, Universidade de Aveiro, 3810 Aveiro, Portugal
}

\begin{abstract}
We report on the lattice location of $\mathrm{Er}$ in $\mathrm{SrTiO}_{3}$ single crystals using the emission channeling technique. The angular distribution of conversion electrons emitted from ${ }^{167 \mathrm{~m}} \mathrm{Er}\left(\mathrm{T}_{1 / 2}=2.27 \mathrm{~s}\right)$ was monitored with a position-sensitive detector following the room-temperature $60 \mathrm{keV}$ implantation of the precursor isotope ${ }^{167} \mathrm{Tm}\left(\mathrm{T}_{1 / 2}=9.25 \mathrm{~d}\right)$ to a dose of $2 \times 10^{12}$ at. $/ \mathrm{cm}^{2}$. The results for the sample annealed in vacuum at $610^{\circ} \mathrm{C}$ for 15 min provide direct evidence that $\mathrm{Er}$ occupies both $\mathrm{Sr}$ and $\mathrm{Ti}$ substitutional lattice sites. In addition, thermal recovery of lattice damage was also studied with $\mathrm{RBS} / \mathrm{C}$ for $\mathrm{SrTiO}_{3}$ implanted to doses of $5 \times 10^{14}$ and $5 \times 10^{15}$ $\mathrm{Er} / \mathrm{cm}^{2}$. We further comment on preliminary photoluminescence results from these samples.
\end{abstract}

Keywords: ion implantation, emission channeling, photoluminescence, radioactive isotopes, $\mathrm{SrTiO}_{3}$ 


\section{Introduction}

Current activities in the area of optical circuits, wave-guides and optical storage systems are promoting crystalline oxides and ceramic materials as relevant media for applications. The possibility of transferring/applying the ion implantation technology, a common method for tuning properties in semiconductors, to these materials would be of great interest once integration is needed. In the particular case of $\mathrm{SrTiO}_{3}$, which has a great potential for applications in microelectronics due to its highly dielectric characteristics, the doping with rareearth elements during growth has been reported to induce changes in its optical and electrical properties [1]. Erbium has major atomic transitions at $1.54 \mu \mathrm{m}, 1.0 \mu \mathrm{m}$ (infrared), $0.537 \mu \mathrm{m}$ and $0.558 \mu \mathrm{m}$ (visible) and is of special interest in the formation of active luminescence centers in implanted semiconductors $[2,3]$. However, to activate the dopants, the implantation damage must be removed. It has been reported that damage recovery in $\mathrm{SrTiO}_{3}$ occurs following thermal anneal in air below $400^{\circ} \mathrm{C}$ [4]. In the following, we present results of lattice site location, lattice reconstruction and luminescence properties of $\mathrm{Er}$ implanted $\mathrm{SrTiO}_{3}$, studied by the emission channeling (EC), Rutherford Backscattering/Channeling (RBS/C) and photoluminescence (PL) techniques.

\section{Methods and Results}

High-quality [001] oriented $\left(5 \times 5 \times 0.2 \mathrm{~mm}^{3}\right) \mathrm{SrTiO}_{3}$ single crystals were used as samples in this study. The Er lattice sites were determined using the EC technique [5] combined with position-sensitive electron detection. The EC technique makes use of the fact that charged

\footnotetext{
*CERN, CH-1211 Geneva 23, Switzerland, guilherme.correia@cern.ch, +4122767 6491
} 
particles emitted from radioactive isotopes in single crystals, experience channeling or blocking effects along low-index crystal directions. This leads to an anisotropic particle emission yield from the crystal surface, which depends in a characteristic way on the lattice sites occupied by the emitter atoms. Implantation was performed at room-temperature using $60 \mathrm{keV}{ }^{167} \mathrm{Tm}$ $\left(\mathrm{t}_{1 / 2}=9.25 \mathrm{~d}\right)$ ions to a dose of $2 \times 10^{12}$ at $/ \mathrm{cm}^{2}$ at the ISOLDE/CERN facility [6]. ${ }^{167} \mathrm{Tm}$ decays into two excited states of ${ }^{167}$ Er with half lives of $1.5 \mathrm{~ns}$ and $2.27 \mathrm{~s}$ [7]. The decay of the $2.27 \mathrm{~s}$ state ${ }^{167 \mathrm{~m}} \mathrm{Er}$ is accompanied by the emission of $\mathrm{K}, \mathrm{L}$ and $\mathrm{M}$ conversion electrons of 150,199 and $206 \mathrm{keV}$, respectively, which have been used in the EC experiments [8]. To measure the conversion electron emission yield as a function of angle towards different crystallographic directions, we used a position sensitive Si detector with an active area of $30 \times 30 \mathrm{~mm}^{2}$ [9]. The position-sensitive detection approach increases the experimental efficiency by one to two orders of magnitude and allows a much faster, easier and more precise determination of lattice sites.

Following room-temperature implantation and the first set of measurements for the as-implanted sample, in-situ annealing was conducted in vacuum (better than $2 \times 10^{-6} \mathrm{mbar}$ ) at $310^{\circ} \mathrm{C}$ and $610^{\circ} \mathrm{C}$ for $15 \mathrm{~min}$ each. Additional ex-situ annealing for the sample was performed in air at $610^{\circ} \mathrm{C}$ for $15 \mathrm{~min}$. After each annealing step, the principal [001], [211] and [111] axes were measured at room temperature. Complementary RBS/C and PL experiments were also done for $\mathrm{SrTiO}_{3}$ samples implanted at room temperature using $160 \mathrm{keV}$ stable ${ }^{167} \mathrm{Er}$ ions to doses of $5 \times 10^{14}$ and $5 \times 10^{15}$ at. $/ \mathrm{cm}^{2}$ at ITN/Sacavém. The samples were subsequently studied using $\mathrm{RBS} / \mathrm{C}$ in the as-implanted state and after annealing in vacuum at $350^{\circ} \mathrm{C}$ for $30 \mathrm{~min}$. The $\mathrm{RBS} / \mathrm{C}$ studies were performed using a $2.0 \mathrm{MeV}^{4} \mathrm{He}^{+}$beam $(1 \mathrm{~mm}$ in diameter). The backscattered particles were detected at $140^{\circ}$ with respect to the incident beam direction using silicon surface barrier detectors with resolutions of 13 and $16 \mathrm{keV}$, respectively. PL measurements have been 
performed with a Bruker 66V Fourier transform spectrometer. The signal was detected with a North-Coast EO-817 liquid nitrogen cooled germanium detector. The $496.4 \mathrm{~nm}$ line of an Ar laser was used for below band gap excitation PL measurements. The samples were mounted on a cold finger of a continuous-flow He cryostat.

Figs 1a,b and c show the normalized emission yield of conversion electrons from the $2.27 \mathrm{~s}$ state of ${ }^{167 \mathrm{~m}} \mathrm{Er}$ in the $\mathrm{SrTiO}_{3}$ crystal following the annealing in vacuum procedure at $310^{\circ} \mathrm{C}$ and $610^{\circ} \mathrm{C}$. Clearly visible are the prominent channeling effects along axial [001], [211] and [111] directions. The combination of these patterns gives direct evidence that a certain amount of ${ }^{167 \mathrm{~m}} \mathrm{Er}$ atoms occupy substitutional sites. To characterize the Er lattice location more precisely, we have carried out computer simulations of emission yields for a variety of sites, including $\mathrm{Sr}$, $\mathrm{Ti}$ and $\mathrm{O}$ substitutional sites, highly-symmetric interstitial sites and displaced positions along the [001], [110] and [111] axes. The concept of electron emission channeling simulations is based on the dynamical theory of electron diffraction, which has been described in detail in Refs. $[5,10]$. Quantitative information is then obtained by comparing the fit of simulated patterns to the observed yields [8,9]. In order to discriminate between various different lattice sites, the characteristics of the $\mathrm{SrTiO}_{3}$ perovskite structure have to be taken into account. For instance, along the [111] direction there are mixed rows of $\mathrm{Sr}$ and $\mathrm{Ti}$ atoms, therefore, the [111] channeling patterns do not allow to discriminate between emitter atoms at the $\mathrm{Sr}$ or Ti site. The [100] and [211] directions, on the other hand, consist of separated rows of $\mathrm{Sr}$ and $\mathrm{Ti}$, and hence provide sublattice sensitivity in that respect. The atomic positions of $\mathrm{O}$ form pure rows along the [111] direction, but along the [100] and [211] directions only $2 / 3$ of the $O$ atoms are on the pure $\mathrm{O}$ rows and the other $1 / 3$ are aligned with $\mathrm{Ti}$ or $\mathrm{Sr}$ atomic strings, respectively. Figs $1 \mathrm{~d}$,e and $\mathrm{f}$ show the best-fit results, which were obtained from a mixture of substitutional fractions: $\mathrm{f}_{\mathrm{Sr}}=22$ $\pm 4 \%$ and $\mathrm{f}_{\mathrm{Ti}}=39 \pm 7 \%$. Significant contributions from emitters on interstitial sites can be ruled 
out, since these would result in a minimum channeling effect along the measured directions. Substitution for $\mathrm{O}$ sites can also be ruled out because the lower charge density along the measured directions would make the EC patterns much more localized along the axes, particularly along the [111]. Consequently, allowing for additional fractions of Er atoms on interstitial or on O sites did not improve the chi square of the fit significantly.

For a visual comparison fig. 2 presents best fits of simulated emission channeling patterns for Er occupying either $\mathrm{Sr}$ or Ti sites in the vicinity of the [001] and [211] axes. As mentioned above, the patterns for Er occupying Sr or Ti sites along the [111] axis are identical and are shown in fig. 1f. The best fits of the simulated patterns were obtained assuming root-mean-square Er displacements of $u_{1}(E r)_{S r}=0.015 \mathrm{~nm}$ at the $\mathrm{Sr}$ sites and of $\mathrm{u}_{1}(\mathrm{Er})_{\mathrm{Ti}}=0.010 \mathrm{~nm}$ at the Ti sites. The remaining Er atoms (39\%) are located at so-called "random sites". Random sites are lattice positions associated with negligible anisotropy in emission yield, i.e. sites of very low crystal symmetry, or sites in heavily damaged or amorphous surroundings.

Fig. 3 shows the mean value for the fractions of emitter atoms at the $\mathrm{Sr}$ and Ti sites, derived from the fits, as a function of annealing temperature. Both the fractions of $\mathrm{Er}$ at the $\mathrm{Sr}$ and $\mathrm{Ti}$ sites increase linearly with annealing temperature and to a $50 \%$ higher value following vacuum annealing at $610^{\circ} \mathrm{C}$ in comparison to the as-implanted state. Further annealing in air at $610^{\circ} \mathrm{C}$ clearly decreases the substitutional fractions, as shown in fig. 3. From the channeling patterns (not shown here), we obtained $\mathrm{f}_{\mathrm{Sr}}\left(610^{\circ} \mathrm{C}\right.$,air $)=0 \pm 6 \%$ and $\mathrm{f}_{\mathrm{Ti}}\left(610^{\circ} \mathrm{C}\right.$,air $)=13 \pm 6 \%$. However, these values are only indicative since the sample surface was visibly changed after the annealing in air. The existence of the two fractions for the implanted Er, predominantly occupying the Ti site, is in contrast with what has been reported in ref. [1], where Er atoms were observed to 
predominantly substitute for $\mathrm{Sr}$ in samples doped during growth. In the present EC experiments, the primary implanted element was ${ }^{167} \mathrm{Tm}$. However, the neutrino recoil energy imparted to ${ }^{167 \mathrm{~m}} \mathrm{Er}$ (below $0.9 \mathrm{eV}$ ), during the ${ }^{167} \mathrm{Tm}$ decay, should not be high enough to move to different lattice sites [7]. Therefore, the Er sites should be mainly determined by the Tm implantation. Still, it is also highly improbable that these two elements have significantly different chemical behavior.

Fig. 4 shows the RBS spectra of samples implanted to $5 \times 10^{14} \mathrm{Er}^{+} / \mathrm{cm}^{2}$ and $5 \times 10^{15} \mathrm{Er}^{+} / \mathrm{cm}^{2}$ at room temperature. The overlap of the aligned and random spectra observed for the highest dose indicates that the amorphization threshold is below this value at room temperature. Annealing at $350^{\circ} \mathrm{C}$ for $30 \mathrm{~min}$ in vacuum has not reduced the width of the damaged region and has not changed the Er profile. These results appear to disagree with ref. [4], where the rate of the epitaxial regrowth of the amorphous $\mathrm{SrTiO}_{3}$ layers, induced by $\mathrm{Pb}$ implantation, was reported to be $0.2-0.3 \mathrm{~nm} / \mathrm{s}$ at $350^{\circ} \mathrm{C}$. To interpret the differences, we must consider the possible influence of the annealing atmosphere or the chemical activity of the implanted species since both can play an important role in the regrowth process. Since we have annealed our samples in vacuum, while in ref.[4] the data was obtained after annealing in oxidizing or dry $\mathrm{N}_{2}$ ambient, we suspect that the annealing atmosphere is playing a crucial role. Similar lattice recovery dependence on the annealing environment has been also found for other oxides, namely sapphire and rutile [11]. For the lower dose of $5 \times 10^{14} \mathrm{Er} / \mathrm{cm}^{2}$, where the amorphous layer was not attained, the annealing produces a significant recovery of the implantation damage (fig. 4). As a result of the annealing, the minimum yield at the Sr damage peak decreases from $54 \%$ to $20 \%$, which is still higher than that for the perfect crystal (2\%). Furthermore, we found the same minimum yield for Er (19.5\%) along the [001] direction, indicating that most of the Er ions are incorporated at substitutional 
sites along this row, in agreement with the EC experiments. Additional PL experiments (figures not included) have shown no luminescence for the as-implanted sample. After annealing, a continuous band appeared roughly from 0.40 to $0.70 \mu \mathrm{m}$ but the characteristic emission lines from the Er activation in the visible region were not observed.

\section{Conclusions}

In summary, we have clearly demonstrated that for a low implanted dose of $2 \times 10^{12}$ at. $/ \mathrm{cm}^{2}$ ${ }^{167} \mathrm{Tm} /{ }^{167 \mathrm{~m}} \mathrm{Er}$ atoms occupy both the $\mathrm{Sr}$ and $\mathrm{Ti}$ sites in $\mathrm{SrTiO}_{3}$, and the Ti substitutional site is a preferred one in contrast with Er doped samples during growth. Annealing in vacuum up to $610^{\circ} \mathrm{C}$ improves the substitutional Er fractions while further annealing in air at $610^{\circ} \mathrm{C}$ decreases the Er substitutional fractions. For doses below $5 \times 10^{14} \mathrm{Er} / \mathrm{cm}^{2}$, vacuum annealing at $350^{\circ} \mathrm{C}$ can significantly recover the damage, however, there is no evidence for optical activation of Er. Further studies are undergoing which aim to understand the influence of temperature, dose and annealing atmosphere on the lattice regrowth and Er optical activation.

\section{Acknowledgments}

FCT (Portugal) is acknowledged for financial support given to J.P.A., for a $\mathrm{PhD}$. grant, under the Praxis XXI program and by project CERN/P/FIS/40125/2000.

\section{References}

[1] L.J. Knott, N. J. Cockroft, J. C. Wright, Phys. Rev. B 51(1995) 5649, and references therein.

[2] S. S. Iyer and Y. H. Xie, Science 260 (1993) 40. 
[3] E.Alves, T. Monteiro, J. Soares, L. Santos, M.F.da Silva, J.C. Soares, W. Lojkowski, D.

Kolesnikov and J. G. Correia, Materials Science \& Engineering B, in press.

[4] C.W. White, L.A. Boatner, P.S. Sklad, C.J. McHargue, J.Rankin, G.C. Farlow and M.J. Aziz, Nucl. Instr. Meth. B 32 (1988) 11; J.C. McCallum, J. Rankin, C.W. White and L.A. Boatner Nucl. Instr. Meth. B 46 (1990) 98

[5] H. Hofsäss and G. Lindner, Phys. Rep. 201 (1991) 123.

[6] E. Kugler et al, Nucl. Instr. Meth. B 70 (1992) 41.

[7] U. Wahl, A. Vantomme, J. De Wachter, R. Moons, G. Langouche, J.G. Marques, J.G.

Correia and the ISOLDE collaboration, Phys. Rev. Lett. 79 (1997) 2069.

[8] U. Wahl, Hyperfine Interactions 129 (2000) 349

[9] U. Wahl, J.G. Correia, S. Cardoso, J.G. Marques, A. Vantomme, G. Langouche and the ISOLDE collaboration, Nucl. Instr. Meth. B 136-138 (1998) 744

[10] H. Hofsäss, Hyperfine Interactions 97 (1996) 247.

[11] C.J. McHargue, J. Hunn, E. Alves, M.F da Silva, J.C. Soares, Nucl. Instr. Meth. B 166-167 (2000) 188 .

\section{Figure captions:}

\section{Figure 1}

Figures (a),(b) and (c) show experimental emission channeling patterns obtained in the vicinity of the [001], [211] and [111] axes, respectively, from ${ }^{167 \mathrm{~m}} \operatorname{Er}(2.27 \mathrm{~s})$ after annealing in vacuum at $610^{\circ} \mathrm{C}$ for $15 \mathrm{~min}$; figures (d),(e) and (f) are the fits to the corresponding data with simulated patterns for Er occupying $\mathrm{Sr}(22 \pm 4 \%)$ and $\mathrm{Ti}(39 \pm 7 \%)$ sites.

\section{Figure 2}

Figures (a) and (b) are best fits of simulated patterns for Er occupying $\mathrm{Sr}$ sites, emitted along the [001] and the [211] axes; figures (c) and (d) are simulated patterns, for Er occupying Ti sites, 
along the [001] and the [211] axes. The simulated pattern for Er occupying Sr and Ti sites along [111] is identical with figure $1 \mathrm{f}$.

\section{Figure 3}

Substitutional fractions of Er occupying $\mathrm{Sr}$ and $\mathrm{Ti}$ sites as a function of annealing temperature in vacuum or in air for 15 min each.

\section{Figure 4}

Random (dashed line) and [001]-aligned RBS spectra for samples implanted to $5 \times 10^{14}$ at. $/ \mathrm{cm}^{2}$ (thin solid line) and $5 \times 10^{15}$ at. $/ \mathrm{cm}^{2}$ (doted line) of stable ${ }^{167} \mathrm{Er}$ and subsequently annealed at 350 ${ }^{\circ} \mathrm{C}$ for

$30 \mathrm{~min}$ for the lower-dose sample. 


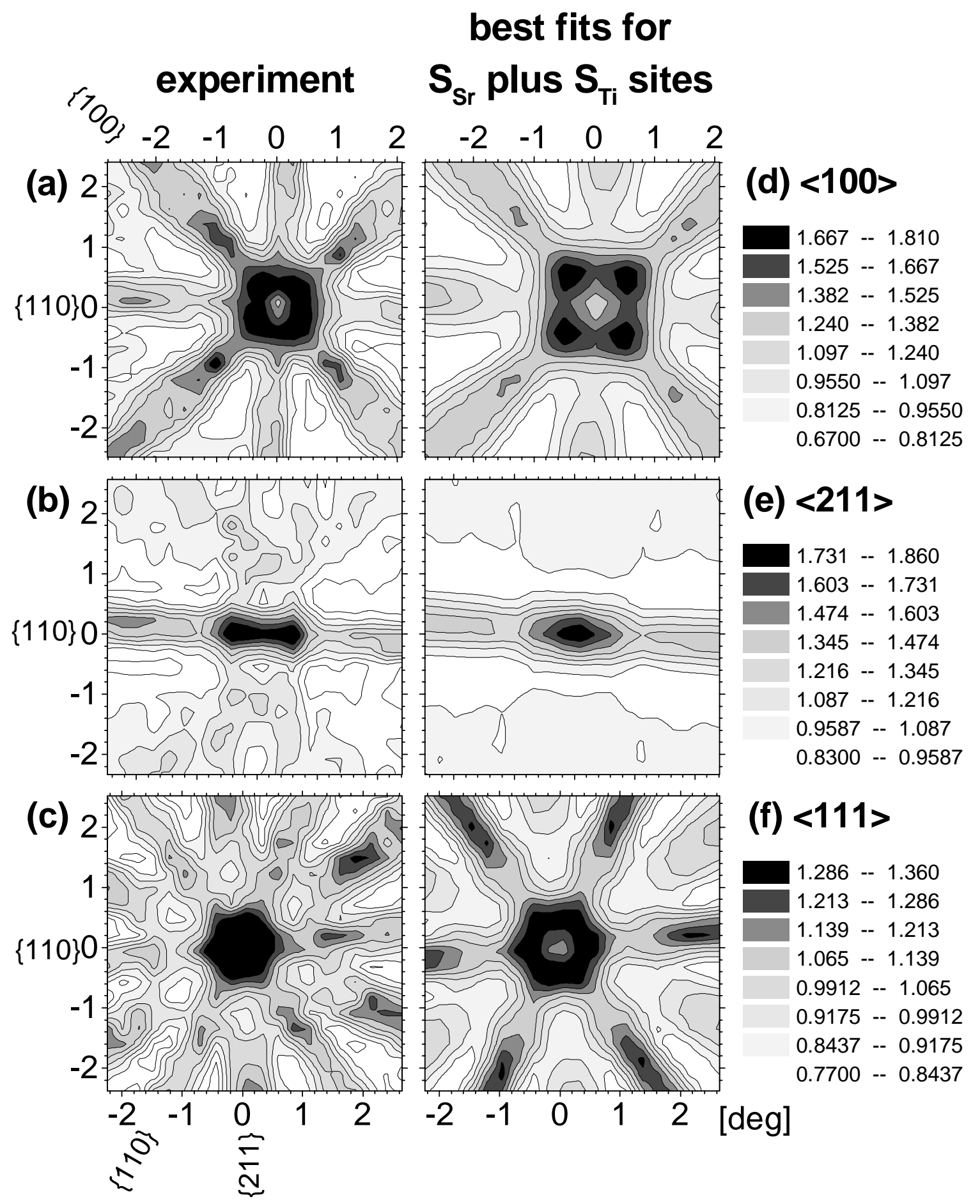

Figure 1 


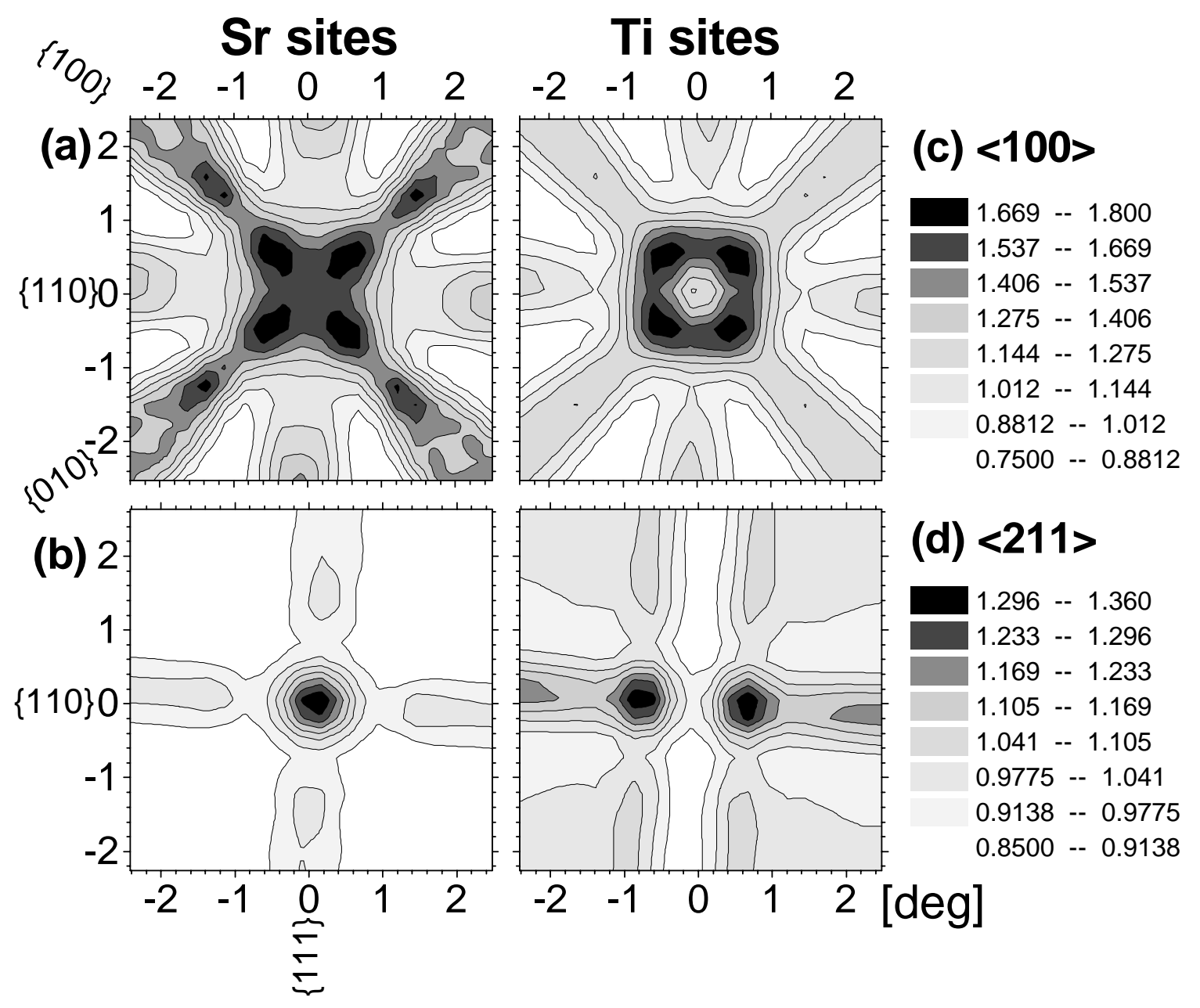

Figure 2 


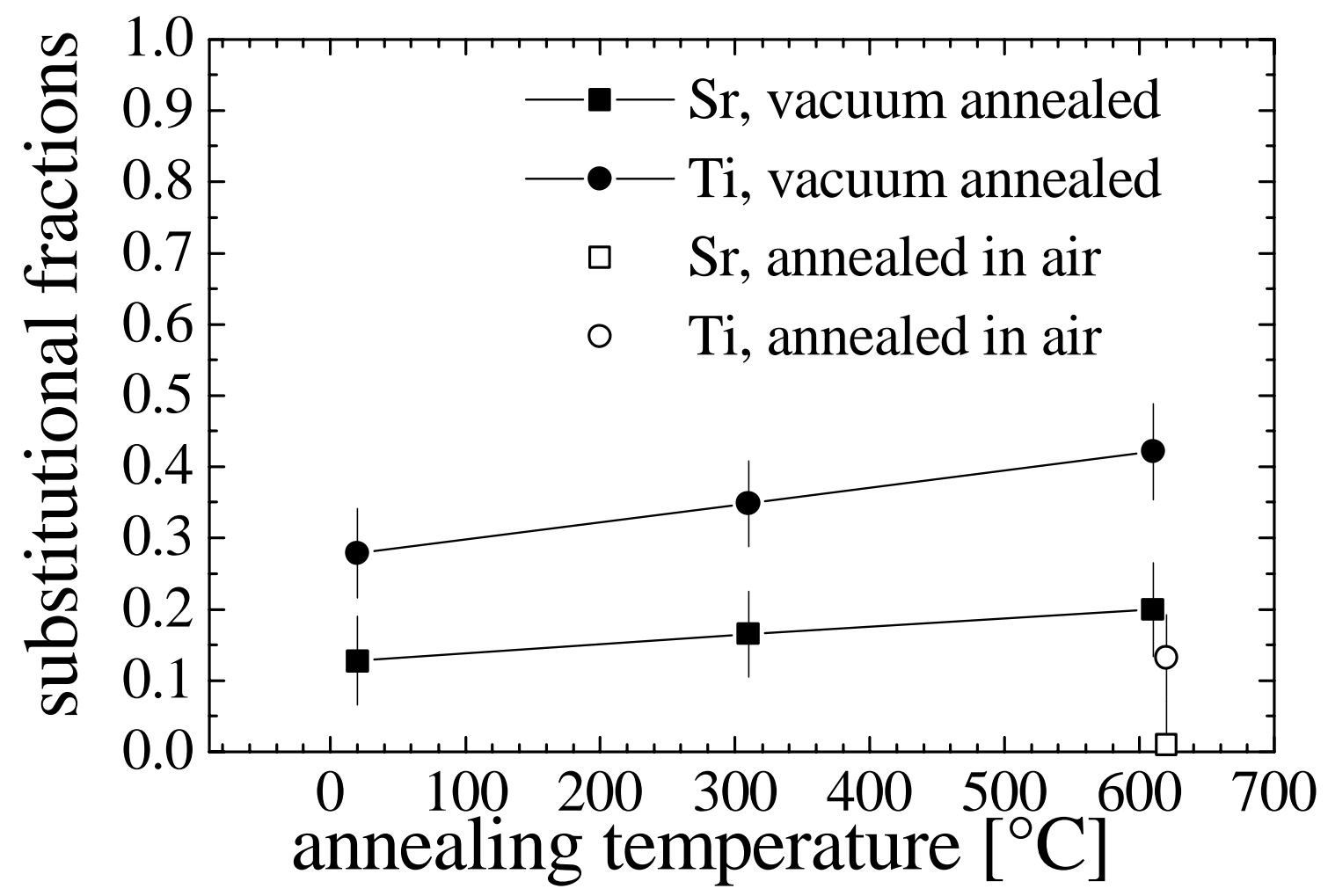

Figure 3 


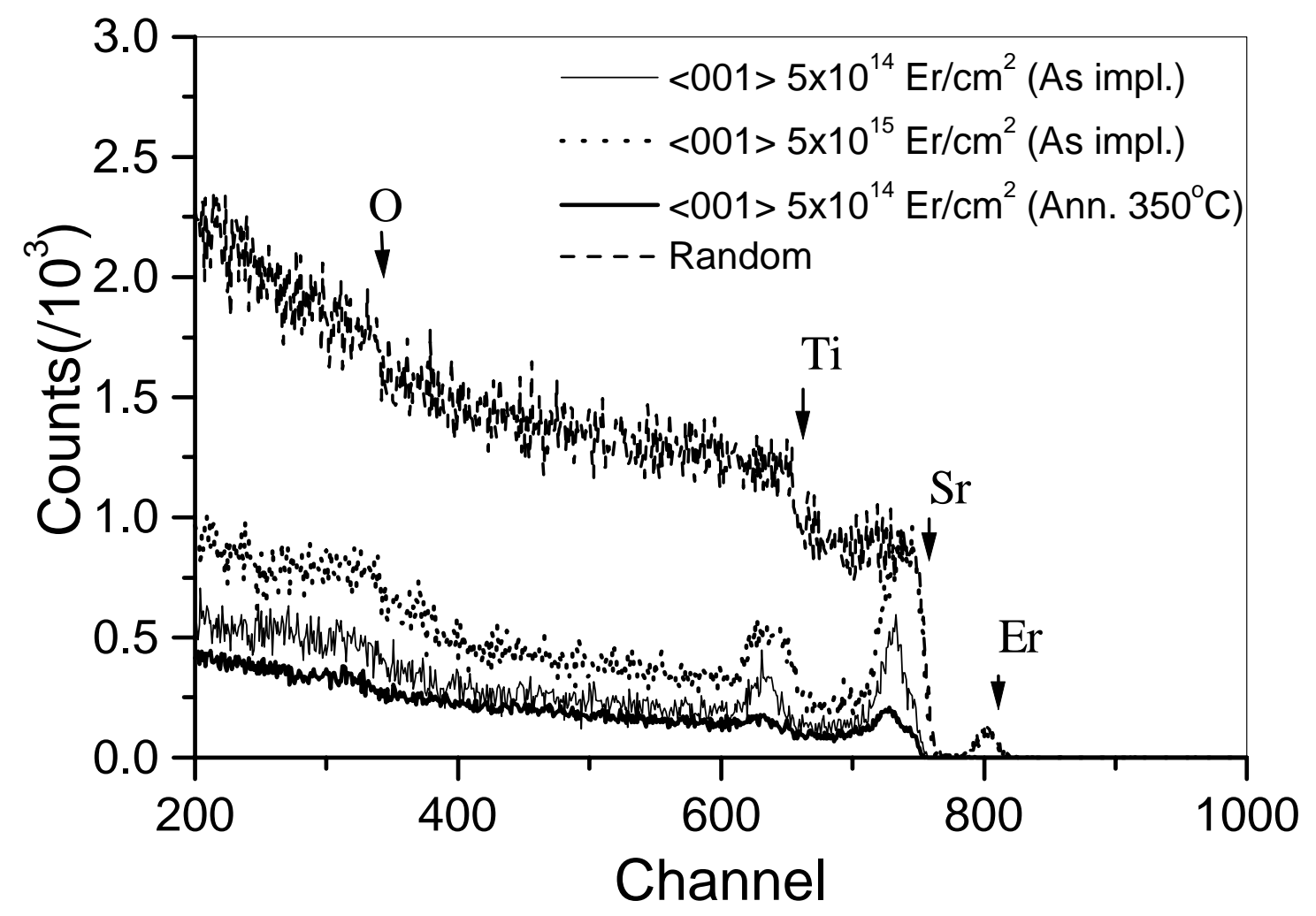

Figure 4

Figure captions:

\section{Figure 1}

Figures (a),(b) and (c) show experimental emission channeling patterns obtained in the vicinity of the [001], [211] and [111] axes, respectively, from ${ }^{167 \mathrm{~m}} \operatorname{Er}(2.27 \mathrm{~s})$ after annealing in vacuum at $610^{\circ} \mathrm{C}$ for $15 \mathrm{~min}$; figures (d),(e) and (f) are the fits to the corresponding data with simulated patterns for Er occupying $\operatorname{Sr}(22 \pm 4 \%)$ and $\mathrm{Ti}(39 \pm 7 \%)$ sites.

Figure 2 